\title{
Polygala fontellana Marques \& Aguiar (Polygalaceae), uma NOVA ESPÉCIE PARA O BRASIL
}

\author{
Maria do Carmo Mendes Marques ${ }^{1} \&$ Ana Cristina Andrade de Aguiar ${ }^{2}$
}

\begin{abstract}
Resumo
(Polygala fontellana Marques \& Aguiar (Polygalaceae), uma nova espécie para o Brasil) Uma nova espécie de Polygalaceae é descrita para os estados da Bahia e Minas Gerais, até o momento endêmica da Cadeia do Espinhaço. Polygala fontellana Marques \& Aguiar pertence ao subgênero Polygala por apresentar carena cristada. São fornecidos descrição, diagnose, ilustração e comentários sobre a sua distribuição geográfica, floração e frutificação.
\end{abstract}

Palavras chave: taxonomia, campo rupestre, flora.

\section{Abstract}

(Polygala fontellana Marques \& Aguiar (Polygalaceae), a new species in Brazil) A new species of Polygalaceae is described from Bahia and Minas Gerais State, currently endemic to Cadeia do Espinhaço. Polygala fontellana Marques \& Aguiar belongs to subgenus Polygala by keel cristate. Description, diagnoses, illustrations and comments about the geographic distribution, phenology are provided.

Key words: taxonomy, campo rupestre, flora.

\section{INTRODUÇÃO}

A família Polygalaceae compreende atualmente 19 gêneros e aproximadamente 1300 espécies, tendo uma distribuição pantropical com um número maior de espécies nos continentes americano e africano (Paiva 1998). É caracterizada pelo pólen policolporado e pelo óvulo anátropo de rafe ventral e epitrópo (Marques 2003). Polygala é o maior gênero da família, distinto dos demais por seus racemos simples, flores zigomorfas, fruto cápsula rimosa, sementes com endosperma e embrião contínuo ou invaginado. Dos doze subgêneros de Polygala, apenas cinco ocorrem em território brasileiro - Acanthocladus, Gymnospora, Ligustrina, Hebeclada e Polygala. De acordo com a classificação infragenérica de Paiva (1998), P. fontellana pertence ao subgênero Polygala por possuir flores com carena cristada.
Polygala fontellana Marques \& Aguiar sp. nov. Tipo: BRASIL. BAHIA: Morro do Chapéu, 2.VIII.2001, fl. e fr., M.C.Marques 423 (Holótipo $\mathrm{RB}$; Isótipo CEPEC, F). Fig. 1

Specie nova Polygala angulata $D C$. affinis sed foliis petiolatis, marginibus revolutis, nervo centrali prominenti et floribus minoribus differt.

Erva a subarbusto escandente, $0,10-1,5 \mathrm{~m}$ alt. Raiz axial ca. $15 \mathrm{~cm}$ compr., levemente sinuosa, ramificada com raríssimas fibrilas finais ou de $7 \mathrm{~cm}$ ramificada desde o terço médio por raízes secundárias que também se ramificam. Caule simples ou 2-5 partindo da base, delgado, estreitamente alado à base do pecíolo, estriado, pubérulo, com tricomas curtos e clavados. Folhas com pecíolo 0,8-1 mm compr., pubérulo; lâmina 1,7-3 ×0,7-1 cm, para a base menores de $1-1,5 \times 0,3-0,4 \mathrm{~cm}$, estreita-ovada a lanceolada, base aguda a raro obtusa, ápice agudo e apiculado, margem revoluta,

\footnotetext{
Artigo recebido em .... Aceito para publicação em .....

${ }^{1}$ Instituto de Pesquisas Jardim Botânico do Rio de Janeiro. Rua Pacheco Leão 915, 22460-030, Rio de Janeiro, RJ, Brasil. mmarques@jbrj.gov.br

${ }^{2}$ Pós-Graduação de Biologia Vegetal, Universidade Estadual de Campinas, Instituto de Biologia, Depto Botânica, Cx. Postal 6109, 13083-970, Campinas, SP, Brasil. acaaguiar@yahoo.com.br
} 
membranácea, pubérula em ambas as faces, com apenas a nervura central proeminente. Racemos terminais $2,5-4,5 \mathrm{~cm}$ ou, com raque desnuda pela queda dos frutos até $12 \mathrm{~cm}$ compr.; raque pubérula, com tricomas clavados; bráctea e bractéolas caducas na flor, com escassos tricomas no dorso e nas margens; bráctea 1,21,5 × 0,8-1 mm, ovada, atenuada para o ápice, aproximadamente duas vezes maior que as laterais ovadas. Botão floral agudo no ápice. Flores subcarnosas, vinosas a liláses; pedicelo 0,2-0,4 mm compr., glabro; sépalas externas abaxiais 1,6-1,7 ×0,8-0,9 mm, ovadas estreitas, a adaxial 1,8-1,9 × 1,7-1,8 mm ovada, ápice obtuso a arredondado; sépalas internas 3,2-3,3 $\times 2,3 \mathrm{~mm}$, elípticas, curto-ungüiculadas, ápice

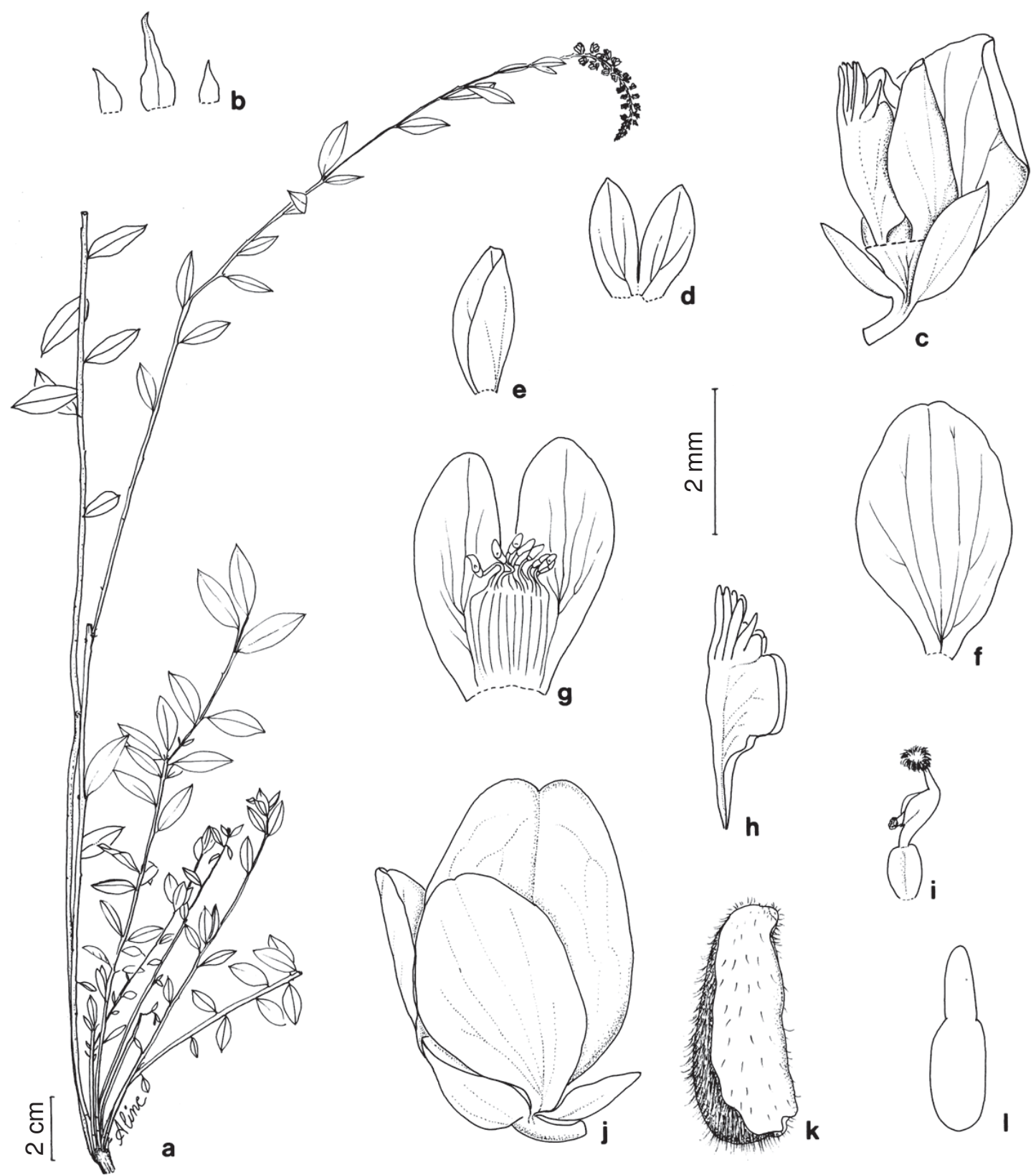

Figura 1 - Polygala fontellana Marques \& Aguiar - a. hábito; b. bráctea e bractéolas; c. flor com a sépala interna seccionada; d. sépalas abaxiais; e. sépala adaxial; f. sépala interna; g. androceu adnato às pétalas laterais; h. carena cristada; i. gineceu; j. fruto com as sépalas persistentes; k. semente apendiculada; 1. embrião. 
retuso, margens revolutas na porção apical, glabras, do mesmo tamanho ou pouco maiores que a corola, com três nervuras partindo da base; carena cristada, incluindo a crista $3-3,2 \mathrm{~mm}$ compr., crista com cerca de quatro pares de lobos bifurcados; parte apical do cúculo no interior dos lobos da crista com uma protuberância sui generis; lobos laterais da crista na altura do ápice da abertura do cúculo; pétalas superiores 3,2-3,3 × 1,5-1,6 mm, elípticas, ápice arredondado, alcançando a carena cristada, com reentrâncias na base do cúculo; estames 8 , bainha estaminal ca. 1,1 mm compr.; filetes livres $0,2-0,3 \mathrm{~mm}$ compr.; anteras deiscentes por poro apical; ovário $1 \times 0,8 \mathrm{~mm}$, suborbicular; estilete ereto, terminado em uma cavidade hipocampiforme cuja a extremidade superior leva um apêndice bem evidente com um tufo de tricomas de cobertura abundantes e a inferior um estigma globoso. Cápsula rimosa 3,4-4×3-3,2 mm, suborbicular, maior ou, raro, do mesmo comprimento das sépalas internas; sementes 3-3,4 × 1,1-1,2 mm, ovadas muito estreitas, densamente pilosas, com tricomas eriçados, ultrapassando o corpo da semente, apendiculadas; apêndices dois, espessos, pubérulos, irregularmente crenulados na extremidade final; embrião 2,5-2,7 mm compr., continuo; eixo hipocótilo-radícula 0,9-1,1 $\times 0,5-$ $0,6 \mathrm{~mm}$, oblongo, cotilédones $1,6-1,8 \times 0,8-1$ mm, elípticos.

Parátipos: BRASIL. Bahia: Morro do Chapéu, 16.II.2004, fl. e fr., G. Pereira-Silva 8462 (CEN, RB); Morrão, 16.VII.1979, fl. e fr., G. Hatschbach 42386 (MBM, RB); Utinga, 1.VI.1980, fl. e fr., R. M. Harley 22979 (RB); estrada para Utinga, 18.VII.2001, fl. e fr., V. C. Souza 26400 (ESA). Minas Gerais: Grão-Mogol, estrada do campo de aviação, 14.VI.1990, fl. e fr., $R$. Simão-Bianchini CFCR 13003 (SPF); mata montana na estrada para o Rio Ventania, 5.IX.1990, fl. e fr., $T$. R. S. Silva CFCR 13392 (SPF); estrada para Ventania, 13.XII.1989, fl. e fr., A. Freire-Fierros CFCR 12702 (SPF); morro da Telemig, 12.VI.1990, fl. e fr., G. Hatschbach 54223 (MBM, RB).

Polygala angulata DC. táxon afim de P. fontellana, devido ao hábito delgado e escandente e às flores subsésseis. Porém, apresenta lâmina foliar com três nervuras proeminentes partindo da base.

Polygala fontellana está restrita, até o momento, a Cadeia do Espinhaço nos estados da Bahia e Minas Gerais (Fig. 2), sendo encontrada em altitudes de 750-1150 m s.m., em formações de campo rupestre, com flores e frutos nos meses de fevereiro, junho, julho,

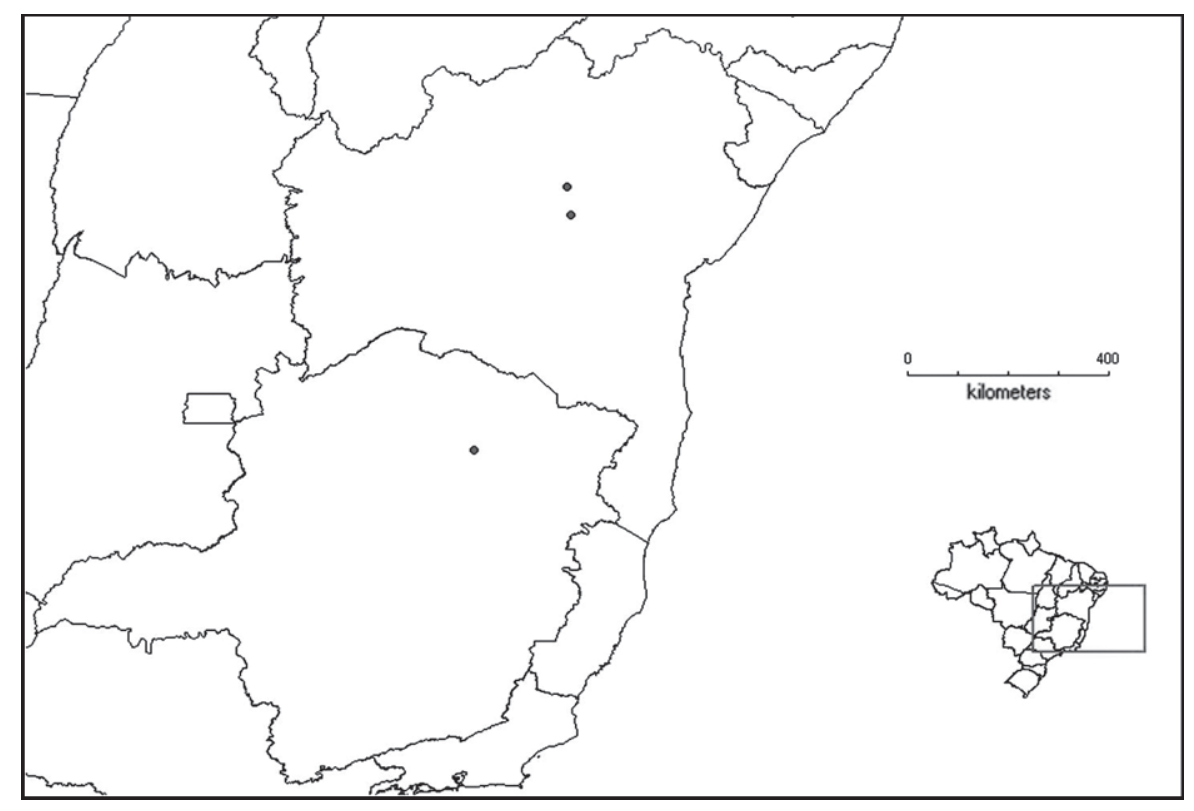

Figura 2 - Distribuição geográfica de Polygala fontellana Marques \& Aguiar. 
agosto, setembro e dezembro. Já Polygala angulata, apresenta uma distribuição maior, ocorrendo além dos estados da Bahia e Minas Gerais, em Goiás, São Paulo e Mato Grosso em formações de cerrado e campo rupestre, com flores e frutos nos meses de janeiro, março, abril, agosto, setembro, outubro e novembro.

O epíteto fontellana é uma homenagem ao Dr. Jorge Fontella Pereira, atual professor pesquisador no Museu Nacional do Rio de Janeiro, que muito tem contribuído para o conhecimento da nossa flora.

\section{REFERÊNCIAS BIBLIOGRÁFICAS}

Paiva, J. 1998. Polygalarum africanarum et madagascariensium prodromus atque gerontogaei generis Heterosamara Kuntze, a genere Polygala segregati et a nobis denuo recepti, synopsis monographica. Fontqueria 50 (1-4): 1-347.

Marques, M. C. M. 2003. Estudo taxonômico do gênero Polygala L. subgênero Ligustrina (Chodat) Paiva (Polygalaceae). Tese de Doutorado. Universidade Federal do Rio de Janeiro, Rio de Janeiro. 